\section{SM Dentistry Journal}

\author{
Article Information \\ Received date: July 19, 2016 \\ Accepted date: Nov 09, 2016 \\ Published date: Nov 10, 2016 \\ *Corresponding authors
}

Abhinav Singh, Department of Dentistry, All India Institute of Medical Sciences (AlIMS), Ministry of Health \& Family Welfare, Govt of India, Bhopal, India, Tel: 91-9752202816, Email: drabhinav. singh@gmail.com

Distributed under Creative Commons CC-BY 4.0

\section{Rescinding a Pugnacious Judgment}

\author{
Bharathi M Purohit ${ }^{1}$ and Abhinav Singh ${ }^{2 *}$ \\ ${ }^{1}$ Department of Public Health Dentistry Peoples College of Dental Sciences \& Research Centre, India \\ ${ }^{2}$ Department of Dentistry, All India Institute of Medical Sciences (AIIMS), Ministry of Health \& Family \\ Welfare, India
}

\section{Editorial}

The highest court in India recalled its controversial verdict of 2013 quashing a Medical Council of India (MCI) notification mandating a common National Entrance-cum-Eligibility Test (NEET) both for undergraduate and postgraduate medical and dental courses in government and private institutions. A bench of Justice Dave, Singh and Goel said that NEET did not infringe upon the rights of the state governments or the private institutions and the single-window test must be applied from this academic year itself [1]. This signifies that no college, together with more than 600 privatelyrun and minority medical institutions, will be allowed to conduct its own entrance examination for selection of students. The bench made its decision on the basis of a petition filed by the MCI.

Medical and Dental Council of India, 2010 amended the regulations on Medical and Dental Education Act, 1997 to make provision for a single eligibility examination test named National Eligibility Entrance Test (NEET) for admission to medical and dental courses. Central Board of Secondary Education was notified to be the institute to conduct NEET [2]. The single window NEET was articulated and implemented based on the prototype and model of the single exam conducted in United States and few other developed countries. The NEET would give students an all-India ranking and a state ranking and students could be admitted either on the basis of their all-India or the state performance if they were to opt for the state quota. The state quota could be used by only those who met the domicile criterion. The NEET had been welcomed by all including the students, parents, medical teachers and general public at large.

The Supreme Court of India, 2013 had retracted NEET and terminated the standardized admission model for medical, dental and postgraduate seats in the country. The majority judgment questioned the practical aspect of holding NEET as in a single competition, expressing the disparity in educational standards in different parts of the country not ensuring a level playing field. Approximately, more than $70 \%$ of medical and $95 \%$ of the dental colleges is private in India. A three-Judge bench by two to one majority struck down NEET as unconstitutional and ruled that the Medical Council of India (MCI) had no authority to issue notifications to regulate admissions to 371 medical and 295 dental colleges as well as postgraduate seats. It was a controversial judgment that brought down the curtain on the tenure of the then Chief Justice of India, Altamas Kabir the very same day. Justice Dave one among the jury disagreed, stating the NEET was valid and was good for the students and citizens at large. He hinted that they were rushed into the judgment by the impending departure of the Chief Justice of India, and that prior to the grounding of the draft judgment, the three judges had no discussion due to lack of time. The judgment endorsed the rights of private medical and dental colleges to frame their own admissions norms and fees structure.

The rationale behind conducting one single test was to bring relief for students who had to turn up for several examinations conducted by numerous colleges at dispersed times and places making students run to many cities and states. Likewise, extremely significant is the complexity in getting admissions to these private medical schools which set their own examination and admission models which are of exceedingly dubious nature and one that promotes a culture of capitation fees. The worthy students with humble financial background have no other option apart from applying for the very limited number of government colleges thereby reducing their chances of a medical seat. The image gets murkier when viewing the post graduation seats within the country $[3,4]$.

A common test ensures that those who get admitted will have an aptitude for the subject. Also significant is the coinciding of many examination dates and the inability of students to appear for the same. The cost of appearing in multiple examinations and the associated reservation regarding the veracity of the same presented a legitimate aspiration of a single test under the government's control. The same has been answered in the recent judgment which once again advocates the common entrance test as the way to go ahead from the current year itself.

Several state governments and many other private and minority institutions are against the NEET. Few states claim that they offer admission on basis of post secondary examinations and that students who have studied in regional language may find it difficult to answer the NEET papers in 
English. Also, NEET is in accordance with the CBSE syllabus and students from other state boards will be at a disadvantage are the cited reasons for being against the common entrance test. However, the ulterior motive being the substantial financial beating which the majority of the institutes will face due to the single admission test Centre due to the pressure from states for reasons stated above passed an ordinance deferring common medical entrance exam to next year, denting the hopes of students for a fair assessment and chances of accomplishing a medical seat without capitation for this year [5].

NEET to a large extent will scuttle the money laundering mills and the associated fraudulent activities. However, the opponents of the same will not sit down quite. The order will be re-challenged via discrete routes alluding infringement on fundamental rights of states and assured constitutional freedom. To realize where we have gone wrong we need honesty of purpose and earnestly articulated issue. The judiciary saw it as a legitimate aspiration of people and the framers of the law did respond to it by rescinding the earlier contentious judgment, supporting the culture of capitation. However, the government has taken an ordinance route to prohibit NEET for the year. Let's hope that the Supreme Court judgment is enacted and monitored and the people at large benefit from next year, till the time the opponents will regroup and advance another shrouded claim describing the test as unfair, unjust and arbitrary.

\section{References}

1. Supreme Court of India. ITEM NO.301. WRIT PETITION (C) NO.261 OF 2016. 2016

2. Purohit B, Singh A. A legitimate aspiration. Journal of Medicine, Health \& Nursing. 2015; 11: 95-98.

3. Singh A, Purohit B. Addressing oral health disparities, inequity in access and workforce issues in a developing country. International Dental Journal. 2013; 63: $225-229$.

4. Singh A. Oral health policies in developing countries. Journal of Public Health Policy. 2010; 31: 498-499.

5. Ruchi Dua. Centre passes ordinance deferring common medical entrance exam to next year. India Today. 2016. 